\title{
The Influence of Sugars and Amino Acids on the Blood- feeding Behaviour, Oviposition and Longevity of Laboratory Colony of Lutzomyia longipalpis (Lutz \& Neiva, 1912) (Diptera: Psychodidae, Phlebotominae)
}

\author{
Nataly A Souza, Claudia A Andrade-Coelho, André F Barbosa, Mauricio L \\ Vilela, Elizabeth F Rangel, Maria P Deane*
}

Departamento de Entomologia *Departamento de Protozoologia, Instituto Oswaldo Cruz, Av. Brasil 4365, 21045-900 Rio de Janeiro, RJ, Brasil

Schneider's Drosophila medium, a complex amino acid rich medium was tested alone and with seven different sugars for some aspects of the biology of Lutzomyia longipalpis.

Statistically significant results were obtained when sucrose was used alone, indicating that among the sugars tested, this is still the most suitable and practical one for the maintenance of L. longipalpis colonies. However, the addition of Schneider's medium to a pool of different sugars, was suggested to be related with the acceptance of the first and second blood meals and to longevity, these being, obviously, quite relevant aspects when transmission experiments are contemplated.

Key words: Lutzomyia longipalpis - carbohydrates - amino acids - honeydew - biology

Sandflies are known to feed on various sweet natural substances (nectar, plant juices, ripe fruits and/or honeydew), which are the only source of food for the non-blood-sucking males. It has been suggested that some of the carbohydrates present in those substances play an important role in the biology of sandflies facilitating the development of Leishmania spp. up to the infective stage in the digestive tract of their vectors (Sherlock \& Sherlock 1961, Lewis 1966, Coelho et al. 1967, Killick-Kendrick 1979, Schlein 1986). An important review on this subject was reported by Molyneux et al. (1991).

The use of raisins as food for females in the laboratory was the first evidence suggesting that the carbohydrates influence the biology of sandflies and the transmission of Leishmania spp. (Smith et al. 1941, Shortt 1945). Later reports have suggested the influence of carbohydrates on the biology of sandflies in the field and laboratory (Barretto 1942, Chaniotis 1967, 1974, Killick-Kendrick et al, 1977, Rangel 1985, Yuval \& Schlein 1986, Schlein \& Yuval 1987, Killick-Kendrick \& KillickKendrick 1987, Dhiman 1988, Brasil \& Ward 1989).

According to Killick-Kendrik (1979) honeydew seems to be a more probable source than nectar, fruit or plant sap. The author gave some reasons for supporting this idea, namely that it can be found

Part of first author MSc Thesis Received 11 November 1994 Accepted 12 July 1995 in all habitats where sandflies are living and that the commonest sugars of honeydew have been demonstrated in the diverticula of sandflies. Similarly, honeydew feeding in wild caught Phlebotomus ariasi in France (Young et al. 1980) following laboratory studies by Killick-Kendrick and KillickKendrick (1987), and selective feeeding of laboratory-kept $P$. papatasi on honeydew has also been recorded (Schlein \& Warburg 1986).

Recently, HPLC (High Performance Liquid Cromatography) was used to demonstrate that honeydew has been considered a natural source of energy for both male and female sandflies. Honeydew is a liquid syrup excreted by aphids or coccids containing carbohydrates and amino acids (Auclair 1963, Brown 1975); glucose, fructose, sucrose, melezitose and its hydrolysis product, turanose, can be found (Moore et al. 1987, MacViker et al. 1990, Wallbanks et al. 1991, Souza et al. 1992).

The studies on the influence of sugar feeding on the biology of sandflies and on the Leishmania-invertebrate host interaction are useful. Several natural foods taken by female sandflies in the field, which are not available in the laboratory feeding, could be related to the development of Leishmania in the sandfly gut and its experimental transmission (Johnson \& Hertig 1970).

Thus, the present study reports the influence of some carbohydrates added or not to Schneider's Drosophila Medium (SDM) on blood meal acceptance and female survival following the first and second blood meal, oviposition and longevity of Lutzomyia longipalpis. 


\section{MATERIALS AND METHODS}

Colony of L. longipalpis - The colony, from Lapinha Cave, State of Minas Gerais, has been in our laboratory for the last 75 generations. The breeding methods have been fully described elsewhere (Modi \& Tesh 1983, Rangel et al. 1985).

Solutions tested - The solutions employed are listed on Table I, and are separated into five groups. The sugars employed in group A were tested in two concentrations and all the solutions were filtered using the Millipore System. The sugars were tested in two concentrations to ascertain if it would be influencing the results. In group B, the saturated solutions were obtained according to Chaniotis (1974). In group C, distilled water was replaced by SDM in order to dilute the sugars employed, namely fructose, sucrose, trehalose, maltose and melezitose. Pools of sugars were employed in groups $\mathrm{D}$ and $\mathrm{E}$, by utilizing distilled water and SDM, respectively. Seven sugars were tested in 21 experiments, including SDM.

The authors decided to test SDM since it is a rich medium which contains amino acids and inorganic salts (Schneider 1964).

Tests with carbohydrates - In this study 5,760 sandflies were distributed among cages with $40 \mathrm{fe}-$ males and 40 males each. The following sugar solutions were tested in eight batches, using 720 sandflies each: (1) fructose $0.75 \mathrm{M}$ and melezitose $0.75 \mathrm{M}$; (2) fructose $1.50 \mathrm{M}$ and melezitose $0.20 \mathrm{M}$; (3) sucrose $1.50 \mathrm{M}$ and maltose $1.50 \mathrm{M}$; (4) fructose and sucrose, both saturated; (5) maltose $0.75 \mathrm{M}$ and sucrose $0.75 \mathrm{M} ;(6)$ maltose and melezitose, both saturated; (7) trehalose and sugar pool, both saturated; (8) trehalose $0.75 \mathrm{M}$ and trehalose $1.50 \mathrm{M}$. In each batch two sugar solutions were tested with the control group (saturated solution of commercial sugar $=$ sucrose $)$ in three repetitions.
Tests with carbohydrates and SDM - In these experiments 1,920 sandflies were distributed among cages containing 40 females and 40 males each. The negative control groups were fed on SDM alone. The following sugar solutions were tested in two batches, using 960 sandflies in each: (1) saturated sucrose + SDM and saturated fructose + SDM; (2) saturated trehalose + SDM and sugar pool and SDM. In each batch two sugar solutions were tested with two control groups.

Observation of sandflies - Only the females were considered in these studies, the males being added for mating. The insects were fed according to Rangel et al. (1985).

After the blood-meal, the fomales (120/experiment) were individually separated in plastic tubes for oviposition and sugar was offered as food. They were observed daily for: proportion of females that had oviposited, number of eggs laid at each oviposition, time between blood feeding and oviposition, and females that survived oviposition. These survivors were transported to a new tube for a second blood meal, and were observed daily until their death. The longevity of females was considered as the time between their emergence until death.

Statistical analysis - The data related to bloodfeeding and the oviposition were converted to percentage and charts using the Harvard Graphics program. The comparison between each treated batch and the control was analyzed through test for difference between two proportions. For the data related to number of eggs laid at each oviposition and longevity the Harvard Graphics program was employed too. The ANOVA test was used to compare treated batches and control groups, considering $95 \%$ as significance level between averages.

TABLE I

Lutzomyia longipalpis. Carbohydrate solutions used as sugar food

\begin{tabular}{|c|c|c|c|c|c|c|}
\hline \multirow{2}{*}{$\begin{array}{l}\text { Sugar } \\
\text { Fructose }\end{array}$} & \multicolumn{2}{|c|}{$\begin{array}{l}\text { Group A } \\
\text { Molarity }\end{array}$} & \multirow[t]{2}{*}{$\begin{array}{c}\text { Group B } \\
\text { Saturated }\end{array}$} & \multirow[t]{2}{*}{$\begin{array}{c}\text { Group C } \\
\text { Saturated }\end{array}$} & \multirow{2}{*}{$\begin{array}{c}\text { Group D } \\
\text { Saturated } \\
\text { sugar pool }\end{array}$} & \multirow{2}{*}{$\begin{array}{c}\text { Group E } \\
\text { Saturated } \\
\text { sugar pool }\end{array}$} \\
\hline & 0.75 & 1.50 & & & & \\
\hline Sucrose & 0.75 & 1.50 & + & + & $\begin{array}{l}\text { (Fructose } \\
\text { Trehalose }\end{array}$ & + \\
\hline Trehalose & 0.75 & 1.50 & $\begin{array}{l}\text { distilled } \\
\text { water }\end{array}$ & SDM & $\begin{array}{l}\text { Maltose } \\
\text { Sucrose }\end{array}$ & SDM \\
\hline Maltose & 0.75 & 1.50 & & & $\begin{array}{c}\text { Glucose } \\
\text { Raffinose }\end{array}$ & \\
\hline Melezitose & 0.20 & 0.75 & & SDM & Melezitose) & SDM \\
\hline
\end{tabular}




\section{RESULTS}

Sugars were tested in several different experiments, and only the results that were statistically more significant than those obtained by the control groups are shown.

Feeding habits - The addition of SDM with a pool of different sugars showed that $100 \%$ of the treated females were alive and took a blood-feeding at the 5th day after emergence (Fig. 1). A high percentage of live females were seen in the control group and in the group treated with trehalose
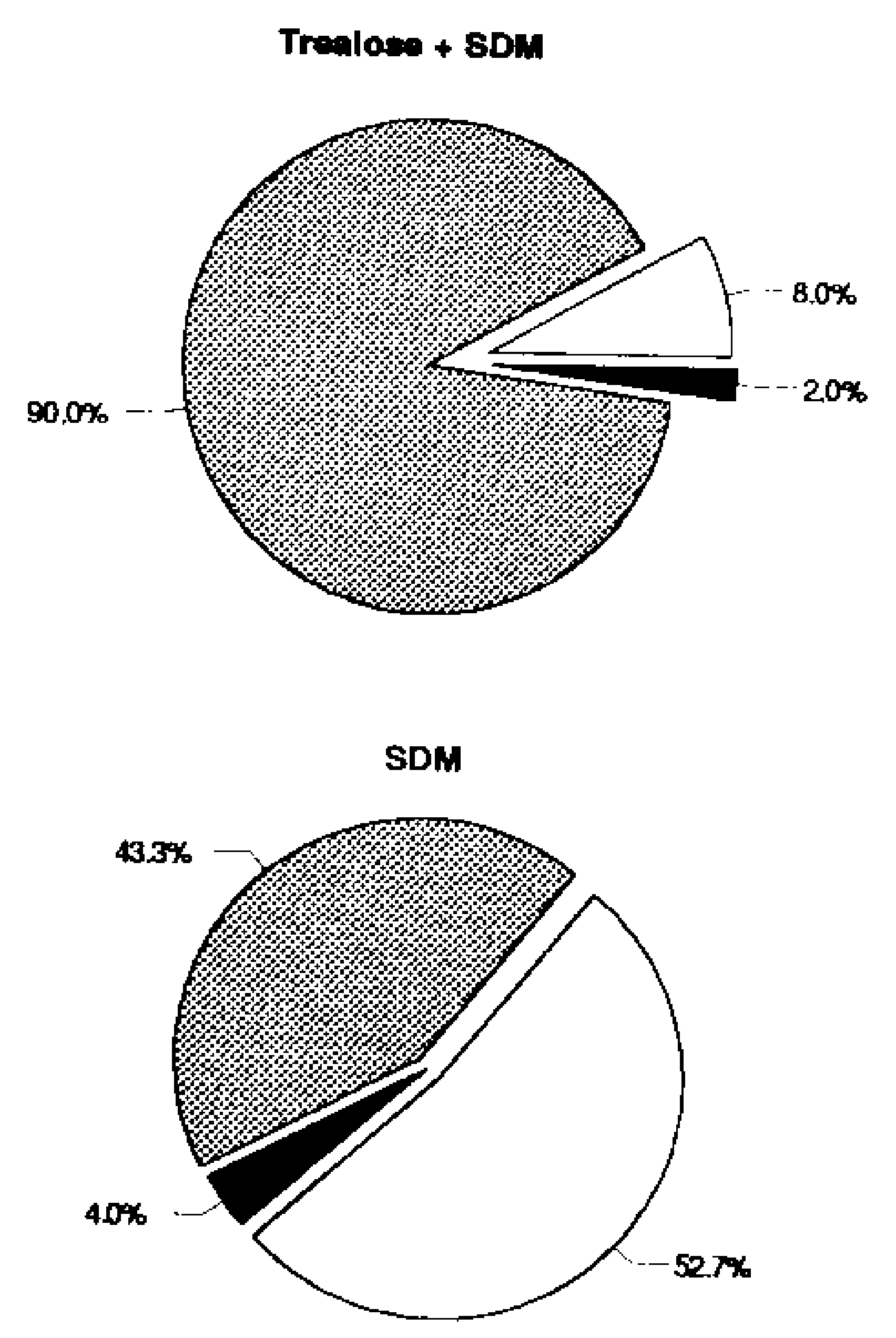

Females dying betore blood feeding added to SDM, too.

Oviposition - No difference was detected between the sandflies fed on different sugars and the control group maintained. as usual, on commercial sugar (sucrose), in regard to the percentage of females performing oviposition (Table II). In relation to the number of eggs per oviposition, the sugar pool added to SDM gave better results: 72.7 eggs/female (Fig. 2). Morever 10 females survived oviposition (Table II), when was offered the sugar pool and SDM.
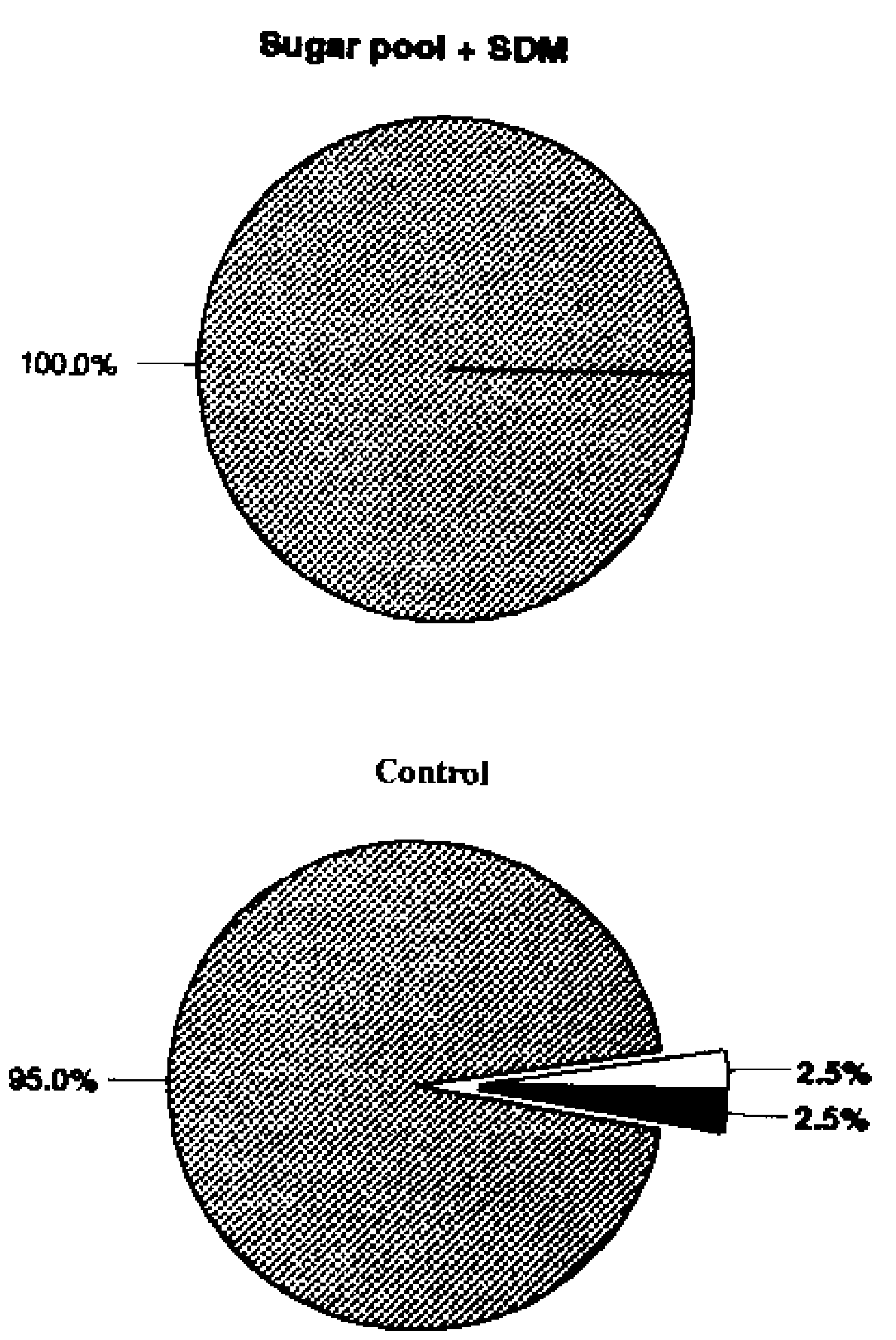

Females didn't feed on blood

Females fed on blood

Fig. 1: Lutzomyia longipalpis. Blood feeding habits: observation at the 5th day.

TABI, F I

Lutzomyia longipalpis. Acceptance of the blood meal and performance of oviposition

\begin{tabular}{|c|c|c|c|c|c|}
\hline Treatment & $\begin{array}{l}\text { Total } \\
\text { females } \\
\text { treated }\end{array}$ & $\begin{array}{l}\text { Acceptance } \\
\text { blood meal }\end{array}$ & $\begin{array}{l}\text { Dead without } \\
\text { oviposition }\end{array}$ & $\begin{array}{l}\text { Dead after } \\
\text { oviposition }\end{array}$ & $\begin{array}{l}\text { Survival to first } \\
\text { oviposition }\end{array}$ \\
\hline $\begin{array}{l}\text { Trehalose set. }{ }^{\dagger} \\
\text { SDM }\end{array}$ & 120 & $\begin{array}{l}108 \\
90 \%\end{array}$ & $\begin{array}{c}7 \\
6.48 \%\end{array}$ & $\begin{array}{c}101 \\
93.52 \%\end{array}$ & $\begin{array}{c}0 \\
0 \%\end{array}$ \\
\hline Sugar pool + SDM & 120 & $\begin{array}{c}120 \\
100 \%\end{array}$ & $\begin{array}{c}3 \\
2.50 \%\end{array}$ & $\begin{array}{c}107 \\
89.17 \%\end{array}$ & $\begin{array}{c}10 \\
8.33 \%\end{array}$ \\
\hline $\begin{array}{l}\text { SDM } \\
\text { (negative control } \\
\text { group) }\end{array}$ & 120 & $\begin{array}{c}52 \\
43.33 \%\end{array}$ & $\begin{array}{c}21 \\
40.38 \%\end{array}$ & $\begin{array}{c}31 \\
59.62 \%\end{array}$ & $\begin{array}{c}0 \\
0 \%\end{array}$ \\
\hline Group control & 120 & $\begin{array}{r}114 \\
95 \%\end{array}$ & $\begin{array}{c}3 \\
2.63 \% \\
\end{array}$ & $\begin{array}{c}111 \\
97.37 \%\end{array}$ & $\begin{array}{c}0 \\
0 \%\end{array}$ \\
\hline
\end{tabular}

SDM: Schneider's Drosophila Medium 


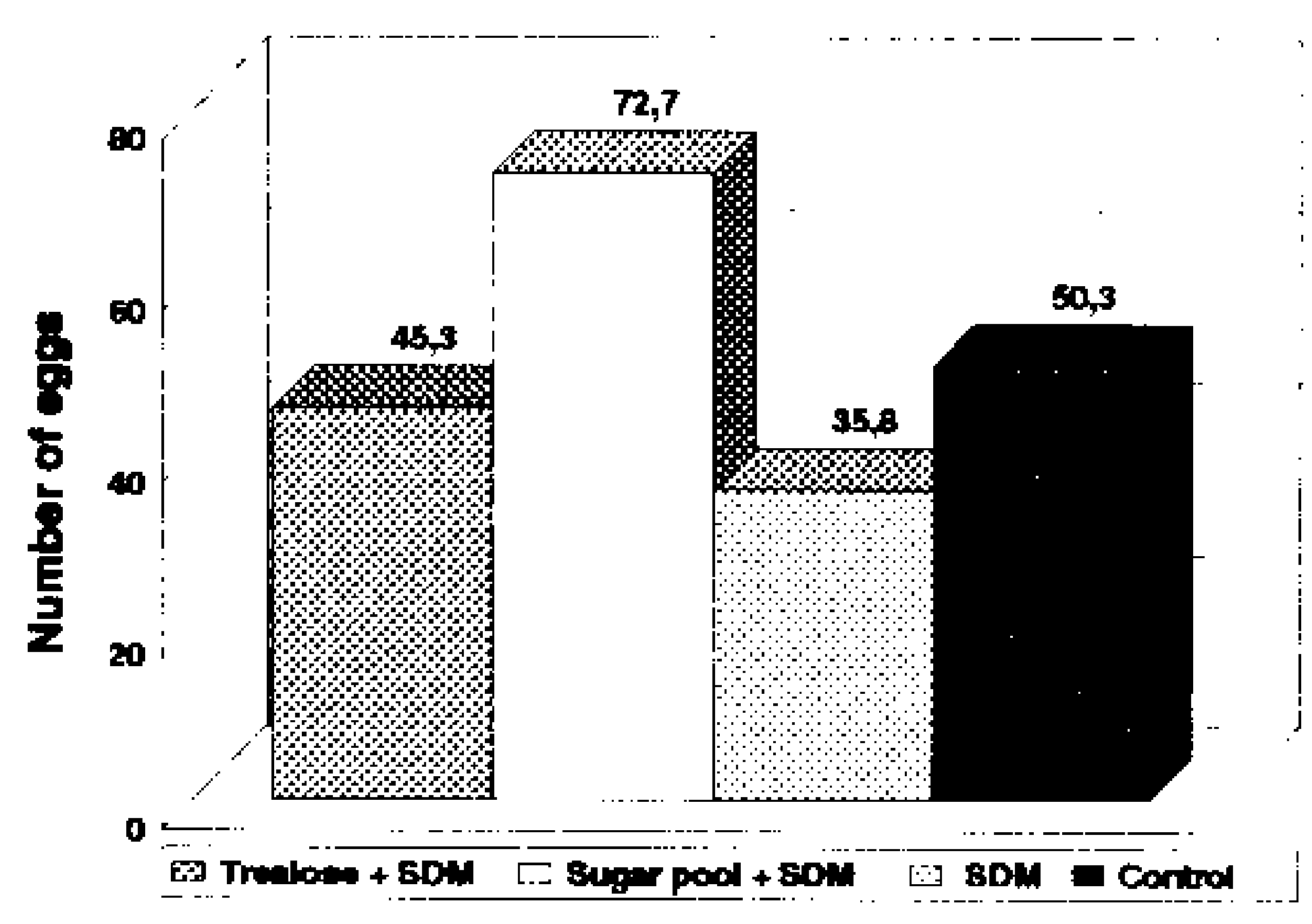

Fig. 2: oviposition of Lutzomyta longtpalpts fed on different sugars.

Longevity - The sugar pool associated with SDM was considered as an important source of energy for female sandflics, since on the 9th day. after the first blood meal. $98 \%$ of the females were alive (Fig. $3)$. and this group survived approximately 15 days (Fig. 4). These females were able to take the second blood meal after the lst oviposition (Table III). without performing the 2 nd oviposition.

\section{DISCUSSION}

The chicf aim of this work was to study some aspects of sugar feeding in laboratory colonies of phlebotomine sandflies in order to obtain maximum longevity and optimize their maintenance. These studies clucidate the importance of sugar meals in experimental studies on sandfly infection by Leishmania, and its transmission in laboratory experiments as well as in nature.

Barretto (1942) and Chaniotis (1967) suggested that female sandflies need to feed on a sugar solution before taking a blood meal.

Although we had observed a high number of females taking blood meal in the sugar pool added to SDM group, our daily experience with a $L$. longipalpis colony has shown that the sugar meal is not essential for the acceptance of blood by the insects. Meanwhile, the same was not observed with the $L$. intermedia colony, since it was necessary to feed the females with a sugar solution during three days before the blood meal. However,

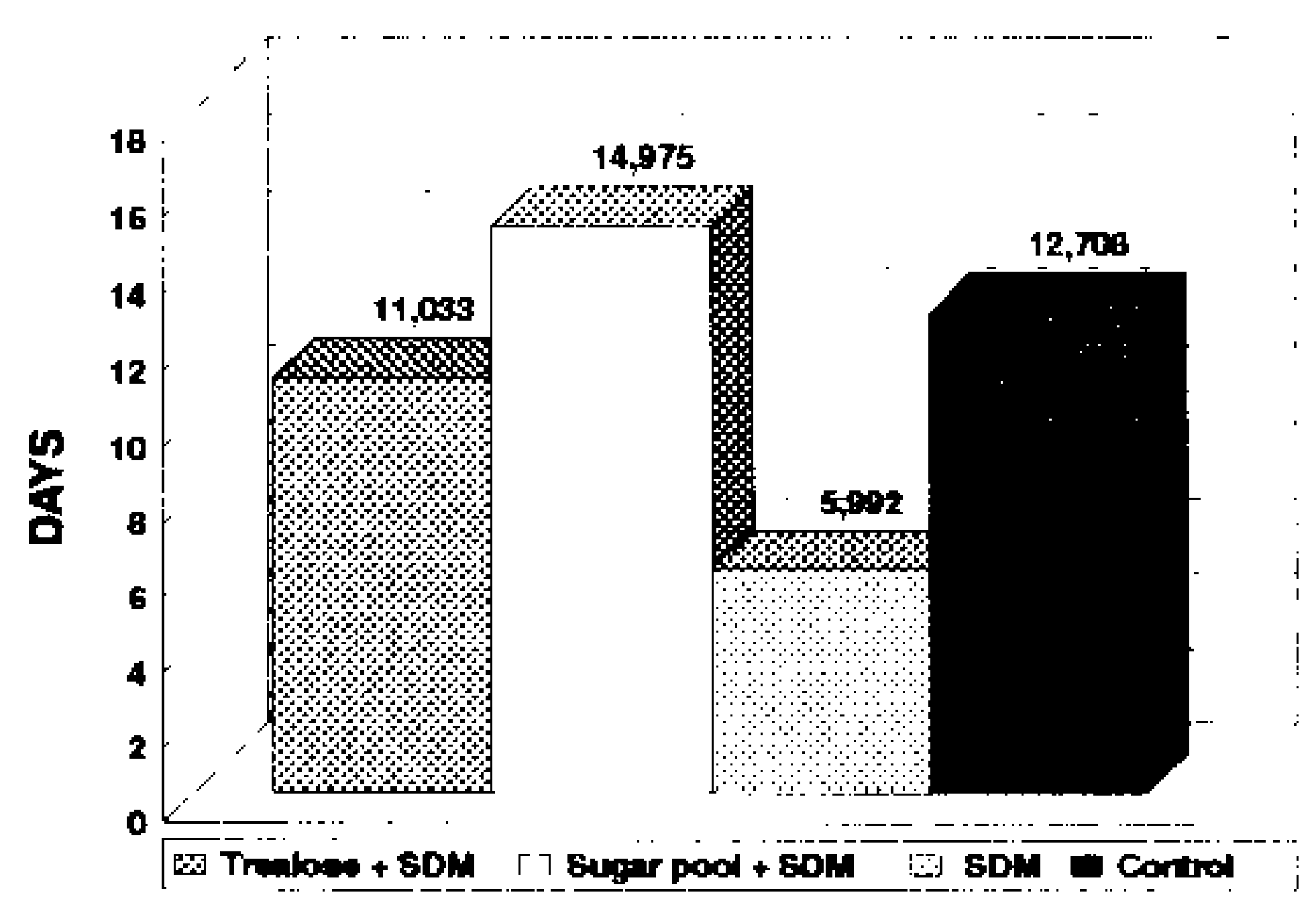

Irig. 4: longevity of Lutzomyia longipalpis fed on different sugars.

\section{Trealose + SDM}

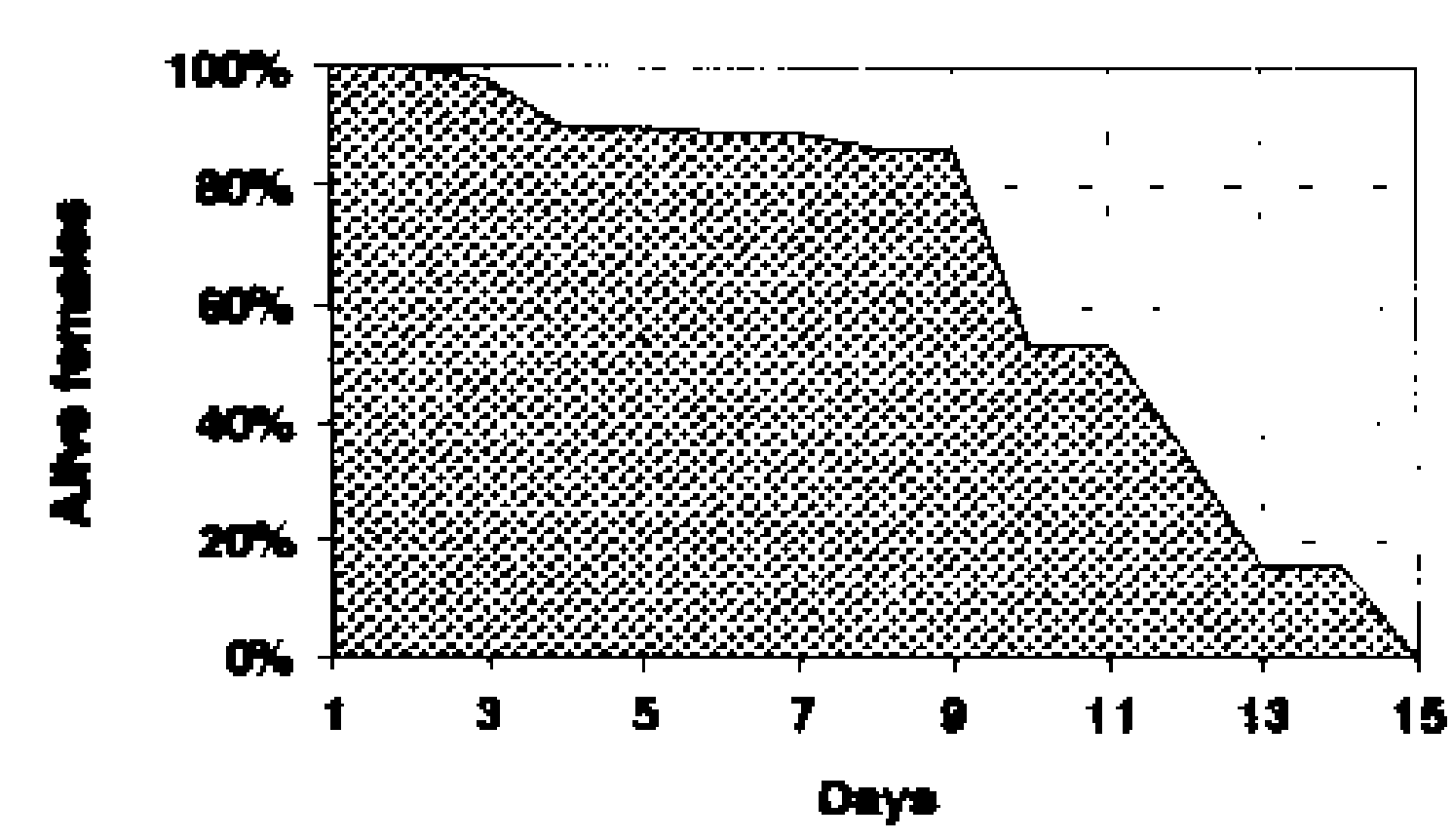

SDM

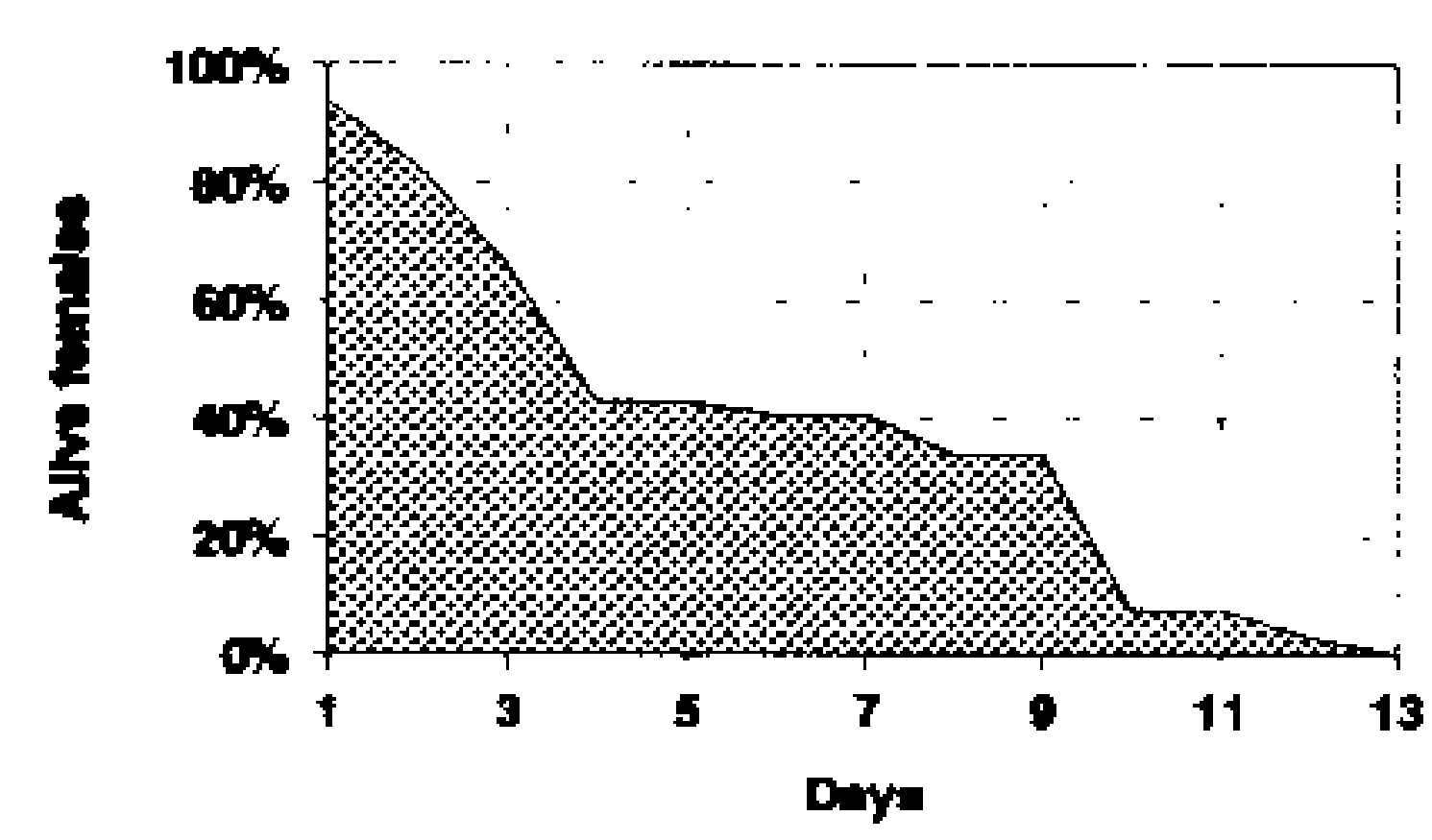

Sugar pool + SDM

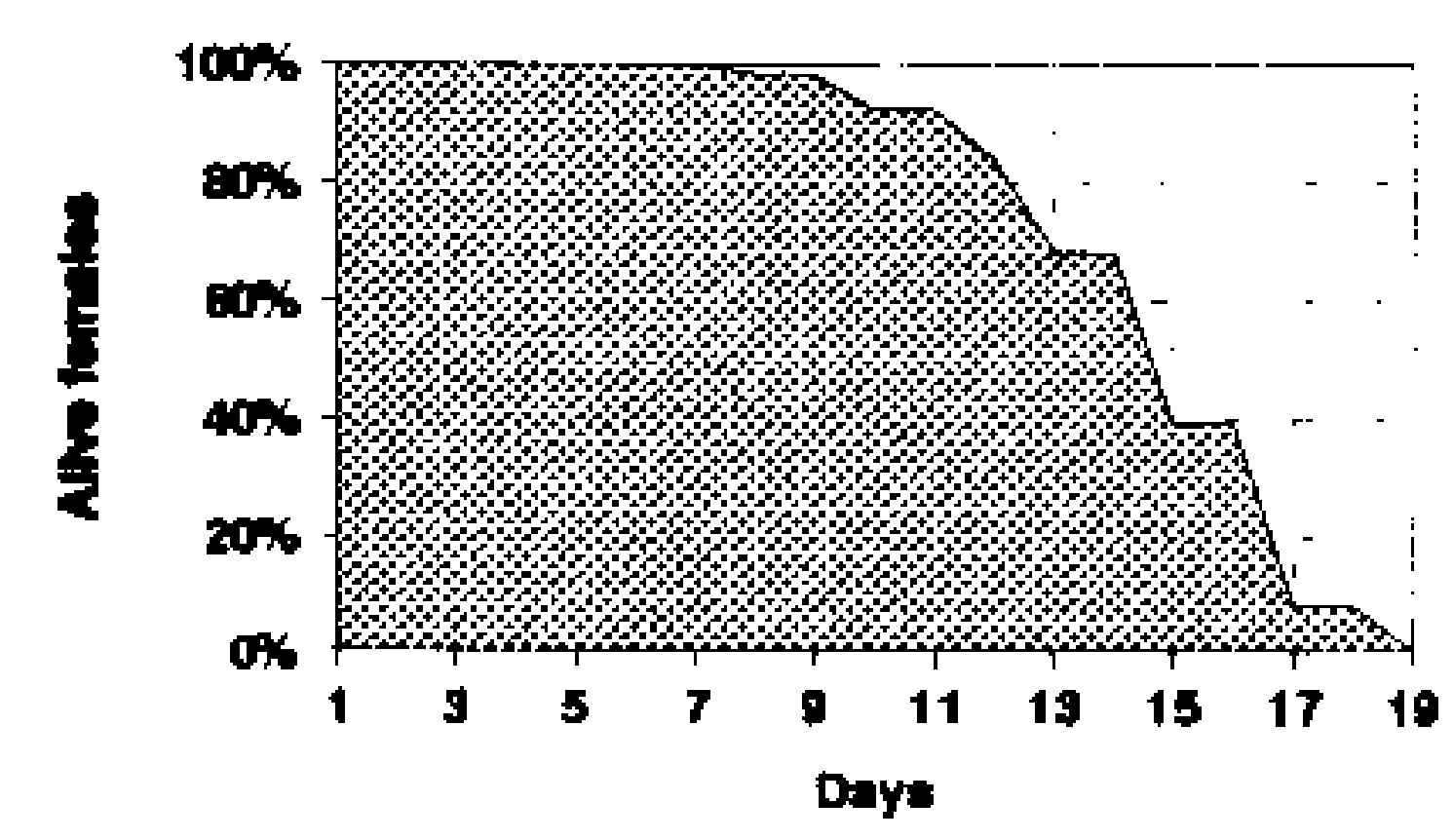

Control

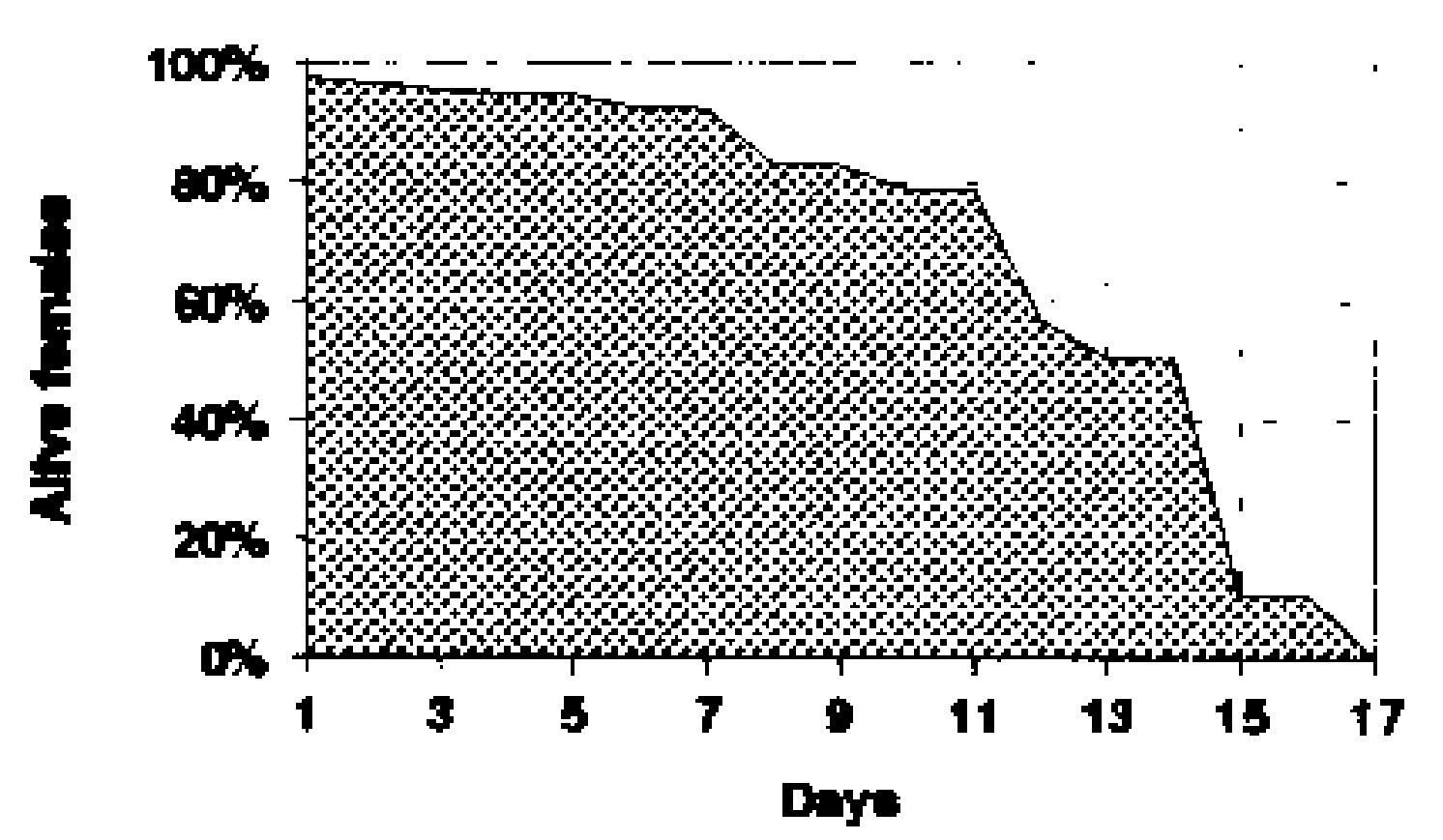

Fig. 3: I,utzomyia longipalpis. Survival on different sugars. 
TABLE III

Lutzomyia longipalpis. Female survival after the oviposition, acceptance of the second blood meal and perfor-

\begin{tabular}{|c|c|c|c|c|}
\hline \multirow[b]{2}{*}{ Treatment } & \multirow[b]{2}{*}{$\begin{array}{c}\text { Total females } \\
\text { treated }\end{array}$} & \multicolumn{2}{|c|}{ mance of second oviposition } & \multirow[b]{2}{*}{$\begin{array}{l}\text { Second } \\
\text { oviposition }\end{array}$} \\
\hline & & $\begin{array}{l}\text { Survival to first } \\
\text { oviposition }\end{array}$ & $\begin{array}{c}\text { Acceptance of } \\
\text { second blood } \\
\text { meal }\end{array}$ & \\
\hline Fructose sat. & 120 & 12 & 0 & 0 \\
\hline Sucrose sat. & 120 & 5 & 0 & 0 \\
\hline Sacharose + SDM & 120 & 1 & 0 & 0 \\
\hline Maltose sat. & 120 & 1 & 0 & 0 \\
\hline Trehalose sat. & 120 & 1 & 0 & 0 \\
\hline Melezitose $0.75 \mathrm{M}$ & 120 & 6 & 0 & 0 \\
\hline Sugar pool & 120 & 8 & 0 & 0 \\
\hline Sugar pool + SDM & 120 & 10 & 10 & 0 \\
\hline
\end{tabular}
second oviposition

our studies indicated that, when the sugar pool was added to SDM, or trehalose was added to SDM, or commercial sucrose was offered to females, it was possible to obtain a high number of insects feeding. This is an important aspect related to the maintenance of laboratory colonies and for studies on experimental infections of sandflies. We believe that female sandflies in nature, which feed on special kinds of sugar, have better conditions to take a blood meal.

In relation to the number of eggs per oviposition, Brazil and Ward (1989) suggested that L. longipalpis females laid more eggs when they received sucrose as a source of food.

On the other hand, Ready (1979) suggested that the egg production per oviposition was related to the blood feeding (size and composition) in L. longipalpis. We think that the optimal conditions of maintenance of laboratory colonies can be related to both sugar and blood feeding.

The present results show that treatment with the sugar pool added to SDM ranks among the ones which had higher rates of egg production than the control treatment. The 13 (fructose $0.75 \mathrm{M}$, saturated fructose, saturated fructose added to SDM, sucrose $1.50 \mathrm{M}$, saturated sucrose, saturated sucrose added to SDM, maltose $0.75 \mathrm{M}$, maltose $1.50 \mathrm{M}$, saturated maltose, trehalose $1.50 \mathrm{M}$, saturated trehalose, saturated trehalose added to SDM and melezitose $0.75 \mathrm{M}$ ) out of the 21 tested treatments (61.9\% of the cases) did not reveal significant differences as compared with the control groups (fed on commercial sucrose). It should be stressed that sucrose, due to its practical aspect, can be indicated as source of sugar in the maintenance of phlebotomine colonies.

According to Killick-Kendrick et al (1977) and Rangel (1985), the utilization of carbohydrates in the laboratory fecding of sandflies would be related with longevity since females which were fed on sugar solutions cxhibited a high survival rate after oviposition. Chaniotis (1974) tested the effect of eleven sugars on L. trapidoi longevity and concluded that five sugars were associated with better results: sucrosc, fructose, maltose, raffinose and glucose. The author suggested that the best sugar food could be highly saturated sucrose or fructose solutions.

Roubaud and Colas-Belcour (1927) commented that a high number of females dying after oviposition was observed in sandfly colonies. Magnarelli and Modi (1988) and Schlein et al. (1992) suggested that the mixture of carbohydrates and proteins (amino acids), as a sugar food to sandflies, could cause higher survival rates and, consequently, positive results in experimental studies on the development of Leishmania spp. in the sandfly vector and the transmission of Leishmania spp. through the bites of female sandflies. Considering the observations related to the acceptance of first and second blood meals, we obtained the best results when the sugar pool added to SDM was employed. We suggest that this kind of sugar food can be employed on a routine basis in experimental studies on the relationship between Leishmania spp. and their vectors.

We believe that the sandflies maintained on sugar pool with a source of amino acids appear to be the ideal diet for both the sandfly and the promastigotes since previous findings have suggested that carbohydrates have a significant role in determining the behaviour of Leishmania in sandflies. It has been shown that there is a chemotaxic response of promastigotes to certain carbohydrates in vitro (Bray 1983) and that growth in a sugar medium induces transformation of 
Leishmania in a manner similar to that the observed in the sandfly (Schlein et al. 1987). The sugar food probably has an important role in the transmission of Leishmania species by their vectors. both in nature and in the laboratory studies, considering that this aspect was demonstrated to be closely related to the females survival and the acceptance of the second blood meal by them, and consequently their vectorial competence. We concluded that the best results were obtained with females fed on the sugar pool added to SDM; this observation provides some indications related to the behaviour of these phlebotomine under natural conditions.

The continuity of these studies investigating the influcnce of sugar feeding on the development of Leishmania spp. in the sandfly vectors will contribute to a better understanding of the transmission of leishmaniasis.

\section{ACKNOWLEDGEMENTS}

Io João Carlos Peixoto for the statistical analysis of the data and Rubens Pinto de Mello for his valuable suggestions.

\section{REFERENCES}

Auclair JL 1963. Aphid feeding and nutrition. Ann Rev Ent 8: 439-440.

Barretto MP 1942. Contribuição para o estudo da biologia dos flebótomos em condições experimentais (Diptera, Psychodidae). Thesis. Faculdade de Medicina de São Paulo. 162 pp.

Bray RS 1983. Chemotaxic responses of promastigotes and macrophages in vitro. J Protozool 30: 322-329.

Brazil RP, Ward RD 1989. Sugar meals, oviposition and survival in laboratory-bred Lutzomyia longipalpis (Diptera: Psychodidae). Mem Inst Oswaldo Cruz 84 129

Brown KC 1975. The chemistr' of aphides and scale insects. Chem Soc Rev 4: 263-288.

Chaniotis BN 1967. The biology of Californian Phlebotomus (Diptera, Psychodidae) under laboratory conditions. J Med Entomol 4: 221-223.

Chaniotis BN 1974. Sugar-feeding behaviour of Lutzomyia trapidoi (Diptera: Psychodidae) under experimental conditions. J Med Ent 1/: 73-79.

Coelho MV, Falcão AR, Falcão AL 1967. Desenvolvimento de espécies do gênero Leishmania em espécies brasileiras de flebótomos do gênero Lutzomyia França, 1924. I. Evolução de $L$. braziliensis cm flebótomos. Rev Inst Med Trop São Paulo 9: 177-191.

Dhiman RC 1988. Detection of fructose in wild-caught Phlebotomus argentipes and $P$. papatasi in Bihar, India. Trans R Soc Trop Med Hyg 82: 344.

Johnson P, Hertig M 1970. Behavior of Leishmania in Panamanian phlebotomine sandflies fed on infected animals. Exper Parasitol 27: 281-300.

Killick-Kendrick R 1979. Biology of Leishmania in phlebotomine sandflies, p. 395-460. In WHR
Lumsden, DA Evans Biology of Kinetoplastida, vol.2, Academic Press. London.

Killick-Kendrick R, Killick-Kendrick M 1987. Honeydew of aphids as a source of sugar for Phlebotomus ariasi. Med Vet Ent 1: 297-302.

Killick-Kendrick R, Leaney AJ, Ready PD 1977. The establishment, maintenance and productivity of a laboratory colony of Lutzomyia longipalpis (Diptera: Psychodidac). J Med Entomol 13: 429. 440

Lewis DJ 1966. Mechanical transmission of Leishmania. Trans R Soc Trop Med Hyg 60: 419.

Macvicker JAK, Moore JS, Molyneux DH, Maroli M 1990. Honeydew sugars in wild-caught Italian phlebotomine sandflies (Diptera: Psychodidae) as detected by high performance liquid chromatography. Bull Ent Res 80: 339-344

Magnarelli LA, Modi GB 1988. Caloric Determinations of Phlebotomine Sand Flies (Diptera: Psychodidac). J Med Entomol 25: 127-130

Modi B. Tesh RB 1983. Mass rearing sand flies. J Med Entomol 20: 568-569

Molyneux DH, Moore J, Maroli M 1991. Sugars in sandflies. Parassitologia 33: 431-436.

Moore JS, Kelly TB, Killick-Kendrick R, KillickKendrick M, Wallbanks KR, Molyneux DH 1987. Honeydew sugars in wild-caught Phlebotomus ariasi detected by high performance liquid chromatography (HPLC) and gas chromatography (GC). Med Vet Fint 1: 427-434.

Rangel EF 1985. Estudo sobre a biologia de flebótomos, vetores de Leishmanioses - Lutzonyia intermedia (Lutz \& Neiva, 1912) e Lutzomyia longipalpis (lutz \& Neiva, 1912) (Diptera. Psychodidae) em condições experimentais. Msc thesis, Museu Nacional. Universidade Federal do Rio de Janeiro, $154 \mathrm{pp}$.

Rangel EF, Souza NA, Wermelinger ED, Barbosa AF 1985. Estabelecimento de colônia, em laboratório, de Lutzomyia intermedia I,utz \& Neiva (Diptera, Psychodidae, Phlebotominae). Mem Inst Oswaldo Cruz 80: 219-226.

Ready PD 1979. Factors affecting egg production of laboratory-bred Lutzomyia longipalpis (Diptera: Psychodidae). J Med Entomol 5: 413-423.

Roubaud E, Colas-Belcour J 1927. Recherches biologiques sur les phlebotomes de la Tunisie du Nord (méthode d'isolemente cellulaire pour l'education selectionée des espéces). Arch Inst Pasteur Tunis 16: 59-80.

Schlein Y 1986. Sandfly diet and Leishmania. Parasitol Today 2: $175-177$.

Schlein Y, Borut S, Greenblatt COL 1987. Development of sandfly forms of Leishmania major in sucrose solutions. J Parasitol 73: 797-805.

Schlein Y, Jacobson RL, Messer G 1992. Leishmania infections damage the feeding mechanism of the sandfly vector and implement parasite transmission by bite. Proc Natl Acad Sci USA 89: 9944-9948.

Schlein Y, Warburg A 1986. Phytophagy and the feeding cycle of Phlebotomus papatasi (Diptera: Psychodidae) under experimental conditions. $J \mathrm{Med}$ Entomol 23: 11-15. 
Schlein Y, Yuval B 1987. Leishmaniasis in the Jordan Valley. IV. Attraction of Phlebotomus papatasi (Diptera: Psychodidae) to plants in the field. $J \mathrm{Med}$ Entomol 24: 87-90.

Schneider I 1964. Differentiation of Larval Drosophila Eye-antenal dises in vitro. J Exp Zool 156: 91-104.

Sherlock IA, Sherlock VA 1961. Sobre a infecção experimental de Phlebotomus longipalpis pela Leishmania donovani. Rev Bras Biol 21: 409-418.

Shortt IIE 1945. Recent research on kala-azar in India. Trans $R$ Soc Trop Med Hyg XXIX: 13-41.

Smith ROA, Halder KC, Ahmed I 1941. Further investigations on the transmission of Kala-azar. Part IV. A second series of transmission of $L$. donovani by $P$. argentipes. Ind Jour Med Res 29: 799-802.

Souza NA, Coutada LCM, Andrade CA, Vilela MI, Rangel EF, Deane MP 1992. Carbohydrates in wildcaught Lutzomyia intermedia (Lutz \& Neiva, 1912)
(Diptera: Psychodidae: Phlebotominae) as detected by high performance liquid chromatography. Mem Inst Oswaldo Cruz 87: 208.

Wallbanks KR, Moore JS, Bennett LR, Soren R, Molyneux DH, Carlin JM, Perez JE 1991. Aphid derived sugars in the neotropical sandfly: Lutzomyia peruensis. Trop Med Parasit 42: 60-62.

Young CJ, Tumer DP, Killick-Kendrick R, Rioux JA, Leaney AJ 1980. Fructose in wild-caught Phlebotomus ariasi and the possible relevance of sugars taken by sandflies to the transmission of leishmaniasis. Trans R Soc Trop Med Hyg 74: 363366.

Yuval B, Schlein Y 1986. Leishmaniasis in the Jordan Valley. III. Nocturnal activity of Phlebotomus papatasi (Diptera: Psychodidae) in relation to nutrition and ovarian development. JMed Entomol 23: 411-415. 